\title{
Temperature Dependent Mechanical Analysis of Chalcogenide (CdS, ZnS) Coated PET Films
}

\author{
Sandhya Gupta, ${ }^{1}$ Kananbala Sharma, ${ }^{2}$ and N. S. Saxena ${ }^{2}$ \\ ${ }^{1}$ Kautilya Institute of Technology \& Engineering, Sitapura, Jaipur 302022, India \\ ${ }^{2}$ Semiconductor and Polymer Science Laboratory, Department of Physics, University of Rajasthan, Jaipur 302004, India \\ Correspondence should be addressed to Sandhya Gupta; 1982sanman@gmail.com and N. S. Saxena; n_s_saxena@rediffmail.com
}

Received 18 February 2013; Accepted 12 March 2013

Academic Editors: W. S. Chow, A. Hashidzume, and J. Puiggali

Copyright (C) 2013 Sandhya Gupta et al. This is an open access article distributed under the Creative Commons Attribution License, which permits unrestricted use, distribution, and reproduction in any medium, provided the original work is properly cited.

\begin{abstract}
Commercial polyethylene terephthalate (PET) film has been used as flexible substrate, and chalcogenide materials such as CdS, ZnS have been coated separately on PET film using vacuum thermal evaporation method. The structural characterisation of CdS-PET and ZnS-PET films has been performed by X-ray diffraction (XRD) pattern and Fourier transforms infrared (FTIR) spectroscopy. The surface morphology of CdS-PET and ZnS-PET films has also been investigated using scanning electron microscope (SEM). Temperature dependent mechanical study of chalcogenide-PET films has been carried out using Dynamic Mechanical Analyser (DMA). The stress-strain curves of chalcogenide coated PET films at room and elevated temperatures explain the mechanical response of these films under the different temperature.
\end{abstract}

\section{Introduction}

Metal chalcogenides (sulfides, tellurides, and selenides) are of great importance for researchers because they are potential candidates for optoelectronic applications such as photodetectors, solar cells, and thin film transistor [1-6]. CdS thin films are regarded as one of the most promising materials for heterojunction thin film solar cells. Wide band CdS $\left(E_{g}=2.4 \mathrm{eV}\right)$ has been used as the window material together with several semiconductors such as $\mathrm{CdTe}, \mathrm{Cu}_{2} \mathrm{~S}$, InP, and $\mathrm{CuInSe}_{2}$ with $14-16 \%$ efficiency $[7,8]$. ZnS thin film has also potential applications in optoelectronic devices such as blue light emitting diodes [9], electroluminescence devices, and photovoltaic cells which enable wide application in the field of displays [10, 11], sensors, and lasers [12].

As the metallized polymer films are used in flexible optoelectronic devices, it is proved by Gupta et al. [13] that most of the metals show excellent adhesion with PET film with the help of stress-strain curves of metalized polymer film for a wide range of temperatures; therefore in the same way an effort has been made to see the effect of wide range of temperatures on chalcogenide (CdS, ZnS) coated polymer film. The change in mechanical stability, stiffness, and elasticity of chalcogenide coated polymer films with temperature is also important issue of study for the application point of view. The mechanical studies of $\mathrm{CdS}$ and $\mathrm{ZnS}$ coated polymer systems at elevated temperatures are very important for the development of light weight optoelectronic devices. In the present work polyethylene terephthalate (PET) film is used as flexible substrate because of its high mechanical strength.

Many techniques have been reported for the deposition of $\mathrm{CdS}$ and $\mathrm{ZnS}$ thin films. These include evaporation, sputtering, chemical bath deposition spray pyrolysis, metal organic chemical vapour deposition (MOCVD), molecular beam epitaxy (MBE) technique, electrodeposition, and photochemical deposition [14-18]. In the present work, thermal evaporation technique has been used for deposition of CdS and $\mathrm{ZnS}$ thin films on PET substrate, as it is simple compared with other new and sophisticated techniques. Here the temperature dependent mechanical studies of these films have been carried out, which help in fabrication of flexible optoelectronic devices.

\section{Experimental}

2.1. Thin Film Preparation. CdS and $\mathrm{ZnS}$ thin films were prepared on PET substrate by evaporation of $\mathrm{CdS}$ and $\mathrm{ZnS}$ 
powder (99.999\% pure, from Alfa Aesar) separately at a residual pressure of $10^{-5}$ Torr. Cleaned PET film of $20 \mu \mathrm{m}$ (from Good Fellow Cambridge Limited, England) was used as substrate, and molybdenum was used as boat source. The thickness of CdS and $\mathrm{ZnS}$ films is same, of the order of $200 \mathrm{~nm}$, which was measured by quartz crystal thickness monitor (Model CTM 200).

2.2. Characterization Study. Structural study of PET, CdSPET, and ZnS-PET films was done using X-ray analysis performed with Philips X'Pert X-ray diffractometer at a scanning rate of $3^{\circ}$ per minute between 10 and $60^{\circ}$. The source used throughout this study was $\mathrm{Cu}, \mathrm{K} \alpha(\lambda=1.5406 \AA)$ operated at $40 \mathrm{~mA}$ and $45 \mathrm{kV}$. The FTIR absorption spectra of these films have been recorded in the frequency region $4000-400 \mathrm{~cm}^{-1}$, using IR spectrophotometer. The accuracy of the measurement is $\pm 4 \mathrm{~cm}^{-1}$ in 4000 to $2000 \mathrm{~cm}^{-1}$ region and $\pm 2 \mathrm{~cm}^{-1}$ in 2000 to $400 \mathrm{~cm}^{-1}$ region. Scanning electron microscopy (SEM) of PET, CdS-PET, and ZnS-PET films has been performed using FEI Quanta $200 \mathrm{~F}$ equipment.

2.3. Mechanical Study. The mechanical properties of CdSPET and ZnS-PET films have been studied by Dynamic Mechanical Analyser (DMA), a sensitive technique that characterizes the mechanical response of materials by monitoring property change with respect to the temperature and frequency of applied sinusoidal stress [19-21]. Samples to be used in DMA were cut into the size between 3-5 $\mathrm{mm}$ in width and $8 \mathrm{~mm}$ in length to conform to the dimensional limits for clamp fixtures in tension mode. The average thickness for each sample was based on separate measurements, taken at the two ends. After mounting the sample in clamp, the furnace was sealed off, scanned over a temperature range from room temperature to $180^{\circ} \mathrm{C}$. The heating/ramp rate was $2^{\circ} \mathrm{C} / \mathrm{min}$ for all temperature scan tests. Frequency of oscillations was fixed at $1 \mathrm{~Hz}$ and strain amplitude $0.01 \mathrm{~mm}$ within the linear viscoelastic region. The storage modulus $E^{\prime}$, loss modulus $E^{\prime \prime}$, and mechanical loss factor (Tan $\delta$ ) have been determined during the test as a function of increasing temperature.

The stress-strain scans for PET, CdS-PET, and ZnS-PET films are taken at room and different elevated temperatures (range from room temperature to $180^{\circ} \mathrm{C}$ ) with constant strain rate of $2 \mathrm{~min}^{-1}$.

\section{Results and Discussion}

\subsection{Structural Study}

3.1.1. X-Ray Analysis. Figure 1 shows the X-ray diffraction patterns of PET, CdS-PET, and ZnS-PET films. X-ray pattern of PET shows the presence of the intense and broader peak in the range of $2 \theta$ from 20 to $30^{\circ}$, which can be assigned to the semicrystalline structure of PET polymer [22, 23]. This observed effect seems to be related to extrusion process (lateral stretching) employed in the production of PET films. When lateral stretching process is not employed, amorphous PET is produced [24].

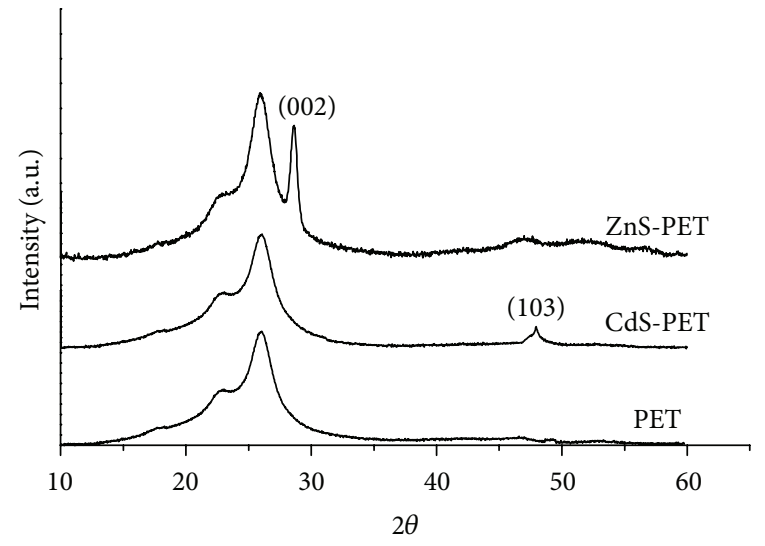

FIGURE 1: X-ray diffraction pattern of PET, CdS-PET, and ZnS-PET films.

The XRD pattern of CdS-PET film shows a peak at $47.89^{\circ}$. It indicates that $\mathrm{CdS}$ is in hexagonal structure with primitive lattice having cell parameter of $a=4.136 \AA, c=6.713 \AA$, and preferred (103) orientation of microcrystallites. Similarly the XRD pattern of ZnS-PET film shows a peak at $28.63^{\circ}$, which reveals that $\mathrm{ZnS}$ is also in hexagonal structure with primitive lattice having cell parameter of $a=3.800 \AA, c=6.230 \AA$, and preferred (002) orientation of microcrystallites. The grain size $(G)$ of $\mathrm{CdS}$ and $\mathrm{ZnS}$ crystallites has been estimated using the following relation [25]:

$$
G=k \frac{\lambda}{(\beta \cos \theta)},
$$

where $k(\approx 1)$ is shape factor, $\lambda$ is the wavelength of $\mathrm{X}$-ray used, $\theta$ is Bragg's angle, and $\beta$ is the FWHM of the peak. The grain size of CdS and $\mathrm{ZnS}$ particles has been found to be of the order of $17 \mathrm{~nm}$ and $15 \mathrm{~nm}$, respectively.

The degree of crystallinity, $X_{c}$, and amorphous content, $X_{a}$, have been calculated [26] using the following relationship:

$$
X_{c}=\frac{I_{c}}{\left(I_{a}+I_{c}\right)}, \quad X_{a}=\frac{I_{a}}{\left(I_{a}+I_{c}\right)},
$$

where $I_{c}$ and $I_{a}$ are the integrated intensities of the crystalline and the amorphous phase, respectively, which can be determined by drawing the line of demarcation in such a manner as to be congruent with the spectrum profile of the films. In this usual method, the area above the demarcation curve has been taken to be proportional to the intensity of crystalline scattering, $I_{c}$, and the area between the baseline and the demarcation curve has been taken to be proportional to the intensity of amorphous scattering, $I_{a}$. The $2 \theta$ values between 10 and $60^{\circ}$ have been considered for crystallinity measurements. Percentage crystallinity of PET, CdS-PET, and $\mathrm{ZnS}$-PET films has been found to be $15.85 \%, 16.63 \%$, and $17.08 \%$ respectively, which indicates that the crystallinity of PET film increases after the deposition of films of metal chalcogenides (CdS, ZnS) on it. 


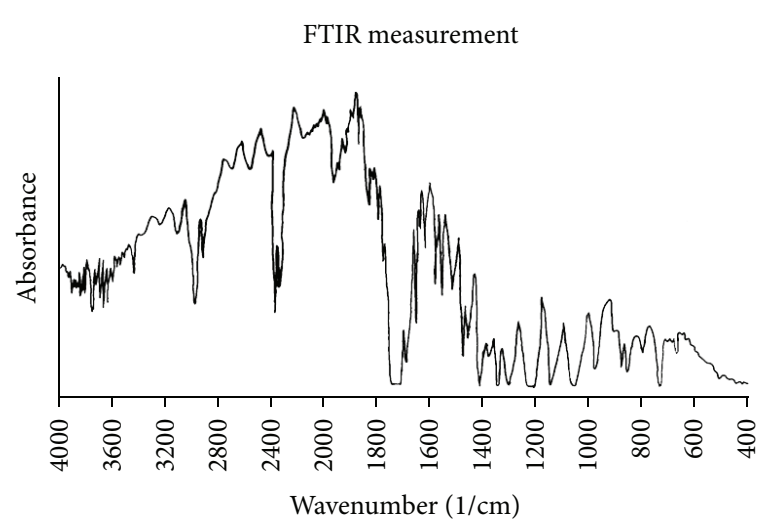

(a)

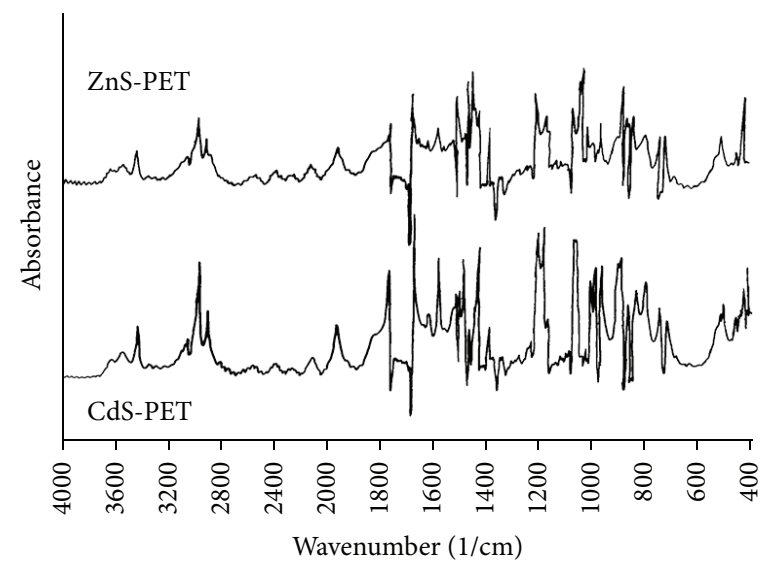

(b)

FIgURE 2: (a) FTIR spectrum of PET film. (b) FTIR spectra of CdS-PET and ZnS-PET films.

SEM analysis

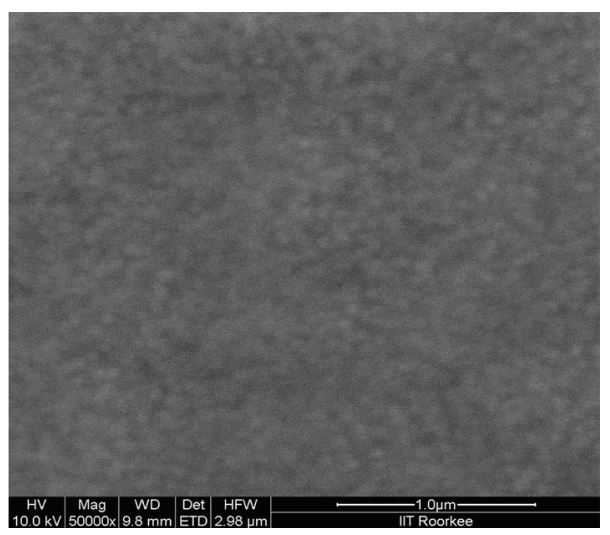

(a)
SEM analysis

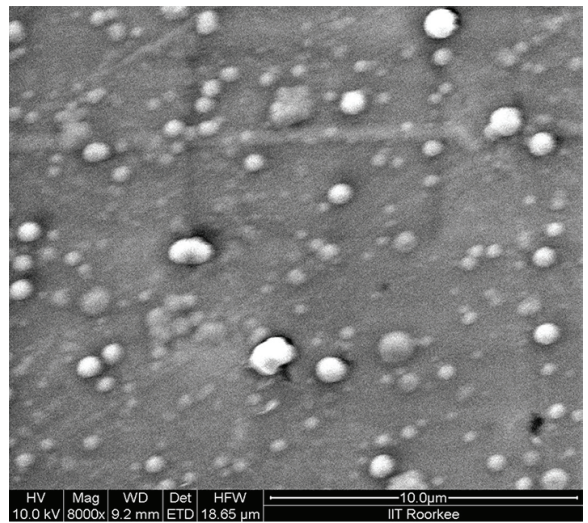

(b)

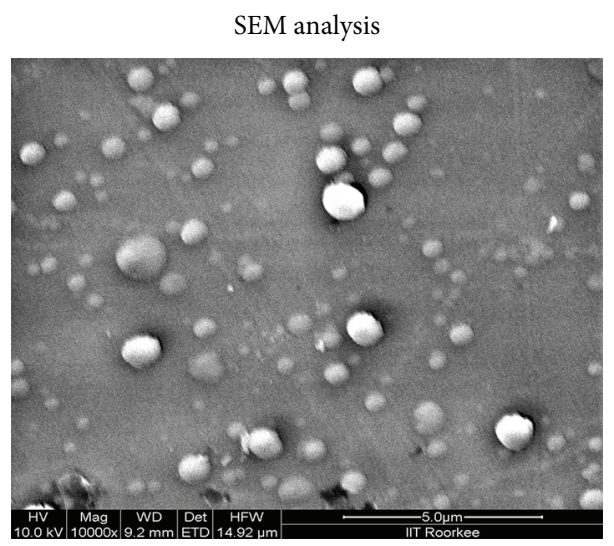

(c)

Figure 3: SEM images of (a) PET, (b) CdS-PET, and (c) ZnS-PET films.

3.1.2. FTIR Measurement. The FTIR spectra of PET and metal chalcogenide (CdS, ZnS)-PET samples in absorption mode have been shown in Figures 2(a) and 2(b), respectively. On comparing the FTIR spectra of PET film to metal chalcogenide-PET films, several new peaks which indicated chemical interaction between PET and chalcogenide (CdS, $\mathrm{ZnS}$ ) have been observed.

The absorption peak at $420 \mathrm{~cm}^{-1}$ is attributed to the vibration of $\mathrm{Zn}^{2+}$ and $\mathrm{Cd}^{2+}$ cations [27]. A sharp band at $1390 \mathrm{~cm}^{-1}$ in FTIR spectra of CdS-PET and ZnS-PET films is 


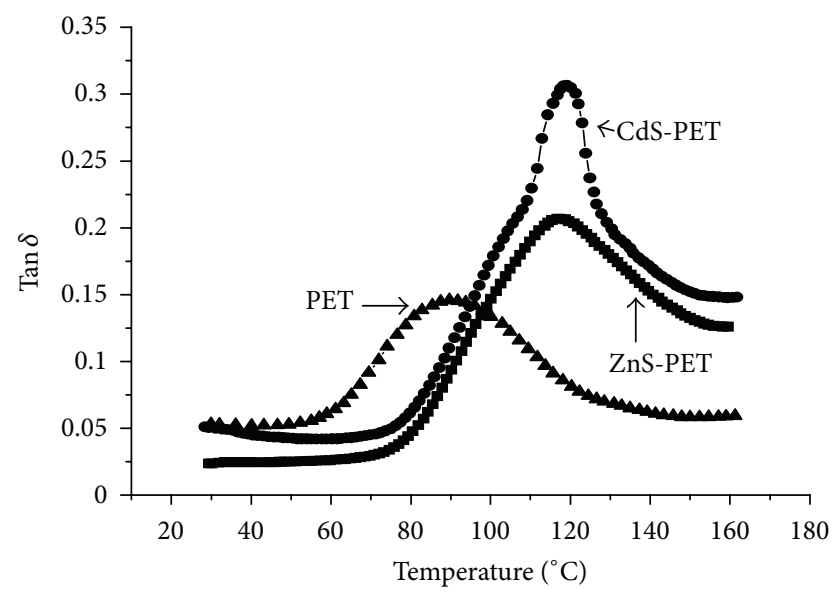

FIgure 4: Variation in Tan $\delta$ with temperature for PET, CdS-PET, and ZnS-PET films.

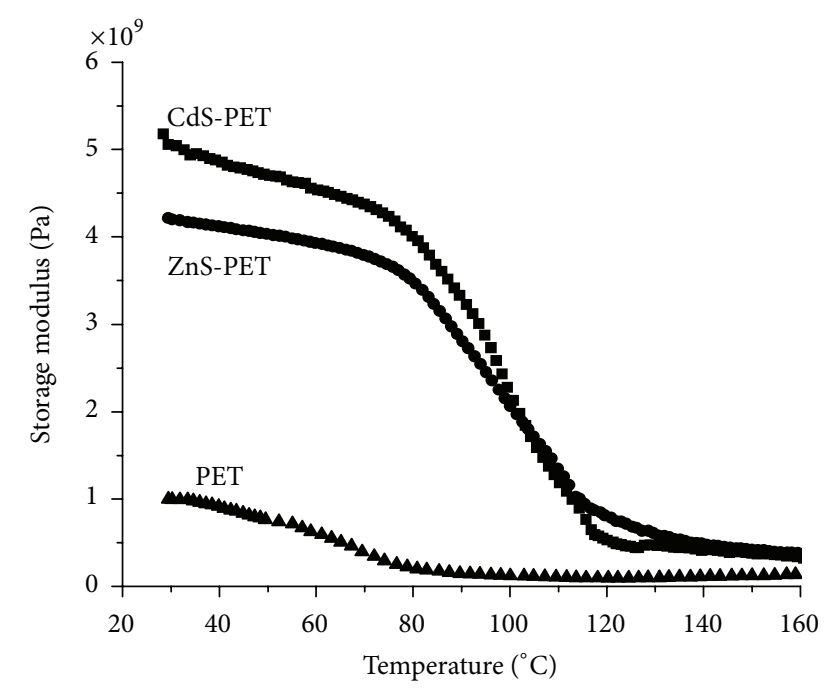

FIGURE 5: Variation of storage modulus with temperature for PET, CdS-PET, and ZnS-PET films.

attributed to C-S stretching [28]. A sharp band at $405 \mathrm{~cm}^{-1}$ in FTIR spectrum of CdS-PET film could be assigned to Cd-S stretching [29]. These bondings confirm that ions of CdS and $\mathrm{ZnS}$ material have been attached to the polymer chain of PET, hence altering its mechanical behaviour.

3.1.3. SEM Analysis. Figures 3(a), 3(b), and 3(c) show the SEM images of PET, CdS-PET, and ZnS-PET films. The CdS-PET, and ZnS-PET films show a globular structure of $\mathrm{CdS}$ and $\mathrm{ZnS}$ molecules of different sizes on surface, while the PET film presents a planner sheet structure. Here it is seen that surface of chalcogenide coated PET film is not as homogeneous as PET film. These images also show the diffusion of CdS/ZnS molecules into the PET base film which are responsible for improving mechanical properties of PET film. It is found that bright chalcogenide particles of the order of $17 \mathrm{~nm}$ of CdS and $15 \mathrm{~nm}$ of $\mathrm{ZnS}$ are dispersed on the polymer surfaces as confirmed by X-ray analysis.

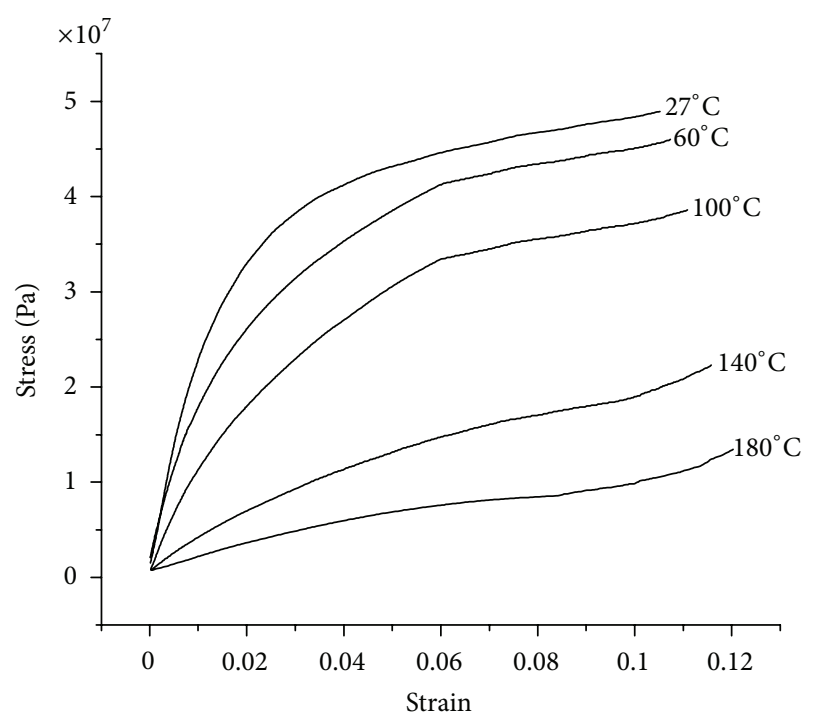

FIGURE 6: Stress-strain curves of PET at room temperature and elevated temperatures.

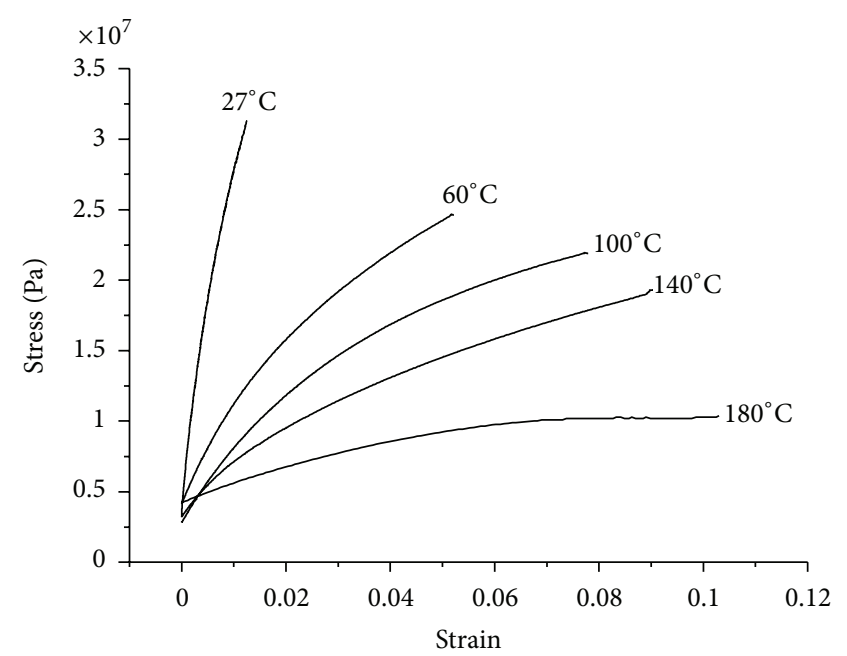

FIGURE 7: Stress-strain curves of CdS-PET film at room temperature and elevated temperatures.

\subsection{Mechanical Study}

3.2.1. Glass Transition Temperature $\left(T_{g}\right)$. Variation in mechanical loss factor with temperature for PET, CdS-PET, and ZnS-PET films has been shown in Figure 4. This figure indicates that the glass transition temperature of CdS-PET and ZnS-PET films is $118.3^{\circ} \mathrm{C}$ and $117.4^{\circ} \mathrm{C}$, whereas the $T_{g}$ of PET film is $89.7^{\circ} \mathrm{C}$. Thus an increase in the value of $T_{g}$ has been observed after coating of $\mathrm{CdS}$ and $\mathrm{ZnS}$ material on PET film. During the coating process ions of CdS and ZnS material have been attached with PET matrix and make a compact structure; therefore CdS-PET and ZnS-PET films take more heat to transform from solid phase to rubbery phase, and glass transition temperature shifts towards the higher temperature. The $T_{g}$ of CdS-PET film is greater than 
TABLE 1: Temperature dependent mechanical properties of PET film.

\begin{tabular}{lccccc}
\hline $\begin{array}{l}\text { Temperature } \\
\left({ }^{\circ} \mathrm{C}\right)\end{array}$ & $\begin{array}{c}\text { Young's modulus } \\
(\mathrm{GPa})\end{array}$ & $\begin{array}{c}\text { Tensile strength } \\
(\mathrm{MPa})\end{array}$ & $\begin{array}{c}\text { Yield strength } \\
(\mathrm{MPa})\end{array}$ & $\begin{array}{c}\text { Fracture energy } \\
\left(\times 10^{-3} \mathrm{~J}\right)\end{array}$ & $\begin{array}{c}\text { Elongation at break } \\
(\%)\end{array}$ \\
\hline 27 & 2.25 & 48.9 & 28.85 & 3.18 & 10.52 \\
60 & 1.61 & 46 & 18.95 & 2.82 & 10.73 \\
100 & 1.07 & 38.6 & 12.69 & 2.38 & 1.15 \\
140 & 0.36 & 22.3 & 4.17 & 1.08 & 11.57 \\
180 & 0.15 & 13.5 & 1.98 & 0.61 & 12.03 \\
\hline
\end{tabular}

TABLE 2: Temperature dependent mechanical properties of CdS-PET film.

\begin{tabular}{lccccc}
\hline $\begin{array}{l}\text { Temperature } \\
\left({ }^{\circ} \mathrm{C}\right)\end{array}$ & $\begin{array}{c}\text { Young's modulus } \\
(\mathrm{GPa})\end{array}$ & $\begin{array}{c}\text { Tensile strength } \\
(\mathrm{MPa})\end{array}$ & $\begin{array}{c}\text { Yield strength } \\
(\mathrm{MPa})\end{array}$ & $\begin{array}{c}\text { Fracture energy } \\
\left(\times 10^{-3} \mathrm{~J}\right)\end{array}$ & $\begin{array}{c}\text { Elongation at break } \\
(\%)\end{array}$ \\
\hline 27 & 2.82 & 31.31 & 21.55 & 0.78 & 1.26 \\
60 & 1.05 & 24.62 & 15.91 & 0.71 & 5.22 \\
100 & 0.65 & 21.91 & 11.55 & 0.53 & 7.80 \\
140 & 0.35 & 19.22 & 9.36 & 0.36 & 9.03 \\
180 & 0.11 & 10.41 & 7.01 & 0.16 & 10.31 \\
\hline
\end{tabular}

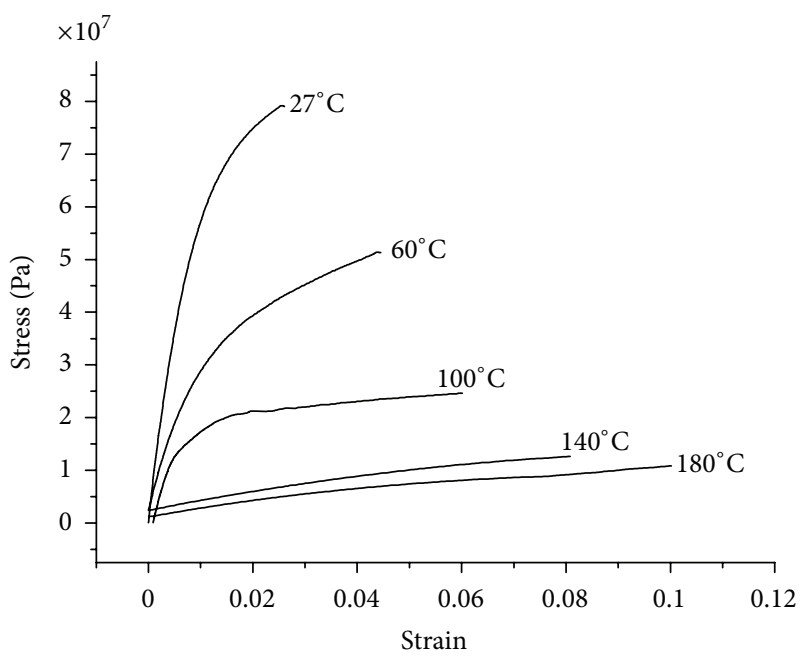

FIGURE 8: Stress-strain curves of ZnS-PET film at room temperature and elevated temperatures.

ZnS-PET film because the size of CdS particle is lower than $\mathrm{ZnS}$ particle as confirmed by XRD results.

3.2.2. Storage Modulus and Tensile Properties. Variation in storage modulus with temperature for PET, CdS-PET, and $\mathrm{ZnS}$-PET films has been shown in Figure 5. From this figure it has been observed that the storage modulus $\left(E^{\prime}\right)$ decreases with increasing temperature due to the softening of these films. The value of storage modulus for PET decreases from $9.98 \times 10^{8}$ to $1.37 \times 10^{8} \mathrm{~Pa}$, as temperature increases from room temperature to $160^{\circ} \mathrm{C}$, whereas the value of storage modulus for CdS-PET and ZnS-PET decreases from $5.18 \times$ $10^{9}$ to $3.2 \times 10^{8} \mathrm{~Pa}$ and from $4.21 \times 10^{9}$ to $3.79 \times 10^{8}$ $\mathrm{Pa}$, respectively, within the same temperature range. It has been found that the value of storage modulus increases after coating of CdS/ZnS on PET film. The reason for the increased value of storage modulus can be assigned to the fact that the ions of CdS and $\mathrm{ZnS}$ material have been attached to the polymer chain of PET as confirmed by FTIR results and make more compact structure. Hence coating of $\mathrm{CdS} / \mathrm{ZnS}$ film increases the stiffness of PET sheet.

The stress-strain behaviour of PET, CdS-PET, and ZnSPET films at room and elevated temperatures has been shown in Figures 6, 7, and 8, respectively. These figures show two characteristic regions and one phase transition for each film. The first region is characterised by an initial linear increase. The second one is characterised by the increase in the strain with a very slow increase of the stress, which is specific for plastic deformation. In this region, the specimen exhibits "irreversible" plastic deformations with increasing strain. The stress in the plastic deformation region varies very little with the strain and is often lower than the yield strength. The transition is indicated as the yield point that corresponds to the onset of plastic deformation events in polymer. The slope of initial linear region of stress-strain curve gives the value of stiffness or Young's modulus of the polymer.

The tensile strength of a polymer is usually defined as the maximum stress reached during the stress-strain test, and the yield strength $\left(\sigma_{y}\right)$ is the point where deviation from linearity occurs in the stress-strain curve. The total area under the stress-strain curve represents the fracture energy or toughness of the sample, and the elongation at break is the maximum strain reached during the stress-strain curve or the value of strain when the sample breaks. The values of Young's modulus $(Y)$, tensile strength $(\sigma)$, yield strength $\left(\sigma_{y}\right)$, fracture energy, and elongation at break for PET, CdS-PET, and $\mathrm{ZnS}$-PET films at room and elevated temperatures have been surmised in Tables 1, 2, and 3 .

The results of Tables 1-3 show the variation of mechanical properties of PET, CdS-PET, and ZnS-PET films with temperature, which indicate the mechanical properties that is Young modulus, tensile strength, yield strength, and fracture energy 
TABLE 3: Temperature dependent mechanical properties of ZnS-PET film.

\begin{tabular}{lccccc}
\hline $\begin{array}{l}\text { Temperature } \\
\left({ }^{\circ} \mathrm{C}\right)\end{array}$ & $\begin{array}{c}\text { Young's modulus } \\
(\mathrm{GPa})\end{array}$ & $\begin{array}{c}\text { Tensile strength } \\
(\mathrm{MPa})\end{array}$ & $\begin{array}{c}\text { Yield strength } \\
(\mathrm{MPa})\end{array}$ & $\begin{array}{c}\text { Fracture energy } \\
\left(\times 10^{-3} \mathrm{~J}\right)\end{array}$ & $\begin{array}{c}\text { Elongation at break } \\
(\%)\end{array}$ \\
\hline 27 & 3.27 & 79.23 & 61.38 & 1.24 & 2.60 \\
60 & 2.16 & 51.32 & 31.26 & 1.18 & 4.45 \\
100 & 1.21 & 24.61 & 15.47 & 0.96 & 6.01 \\
140 & 0.62 & 12.63 & 10.54 & 0.45 & 8.07 \\
180 & 0.38 & 10.87 & 8.06 & 0.38 & 10.01 \\
\hline
\end{tabular}

decrease with increasing temperature, whereas the elongation at break shows increasing behavior with temperature. It is seen that after the coating of $\mathrm{CdS} / \mathrm{ZnS}$ on PET film the value of Young's modulus has been increased, and elongation at break has been decreased. This increase in Young's modulus and decrease in elongation at break of CdS-PET and ZnSPET films are due to the increase in crystallinity of these films because $\mathrm{CdS} / \mathrm{ZnS}$ is polycrystalline material, and when it diffuse in amorphous PET film, it increases crystallinity of PET film.

Tensile and yield strength of ZnS-PET film have also been increased in comparison of PET film due to increase in stiffness or modulus. But it is observed that the tensile and yield strength of CdS-PET film have been decreased in comparison of PET film. This behaviour can be understood on the basis of fracture energy of CdS-PET film. The fracture energy of CdS-PET film is very low in comparison of PET film therefore very less energy is required to break the sample. Hence CdS-PET film shows hard and brittle nature, whereas ZnS-PET film shows hard and ductile nature.

\section{Conclusions}

A systematic study of structural and mechanical characterization of PET and chalcogenide (CdS, $\mathrm{ZnS}$ ) coated PET films leads to the following conclusions.

(1) The structural study of PET and chalcogenide (CdS, $\mathrm{ZnS}$ ) coated PET films indicates that metal and chalcogenide coated PET films are more mechanically and thermally stable in comparison to PET film due to their compact structure.

(2) An increase in glass transition temperature $\left(T_{g}\right)$ of PET film after deposition of chalcogenide semiconductor (CdS, $\mathrm{ZnS}$ ) that is due to increase in crystallinity indicates that the stability of these films increases.

(3) Due to increase in modulus and strength of PET film after deposition of chalcogenide semiconductor (CdS, $\mathrm{ZnS}$ ), these films can survive up to higher temperature and load in comparison to PET film, when used as a substrate in light weight optoelectronic devices.

(4) It is seen that the mechanical viability of PET film has been increased after chalcogenide coating over it.

\section{References}

[1] P. C. DeHart, D. S. Albin, A. Duda et al., in Proceedings of the 17th European Photovoltaic Solar Energy Conference, Munich, Germany, October 2001.

[2] K. Nair, M. T. S. Nair, A. Fernandez, and M. Ocampo, "Prospects of chemically deposited metal chalcogenide thin films for solar control applications," Journal of Physics D, vol. 22, no. 6, p. 829, 1989.

[3] Y. Ueno, H. Minoura, T. Nishikawa, and M. Tsuiki, "Electrophoretically deposited CdS and CdSe anodes for photoelectrochemical cells," Journal of the Electrochemical Society, vol. 130, no. 1, pp. 43-47, 1983.

[4] C. Naşcu, I. Pop, V. Ionescu, E. Indrea, and I. Bratu, "Spray pyrolysis deposition of CuS thin films," Materials Letters, vol. 32, no. 2-3, pp. 73-77, 1997.

[5] J. Touskova, D. Kindl, and J. Tousek, "Photovoltaic cells on CdS/CdTe heterojunctions," Physica Status Solidi (A) Applied Research, vol. 142, no. 2, pp. 539-549, 1994.

[6] M. A. Hasse, J. Qiu, J. M. DePuydt, and H. Cheng, "Blue-green laser diodes," Applied Physics Letters, vol. 59, no. 11, p. 1272, 1991.

[7] B. Su and K. L. Choy, "Microstructure and properties of the CdS thin films prepared by electrostatic spray assisted vapour deposition (ESAVD) method," Thin Solid Films, vol. 359, no. 2, pp. 160-164, 2000.

[8] X. Wu, J. C. Keane, R. G. Dhere et al., "16.5\% efficient CdS/CdTe polycrystalline thin-film solar cell," in Proccedings of the 17th European Photovoltaic Solar Energy Conference, pp. 995-1000, Munich, Germany, October 2001.

[9] S. Coe, W. K. Woo, M. Bawendi, and V. Bulović, "Electroluminescence from single monolayers of nanocrystals in molecular organic devices," Nature, vol. 420, no. 6917, pp. 800-803, 2002.

[10] M. C. Beard, G. M. Turner, and C. A. Schmuttenmaer, "Sizedependent photoconductivity in CdSe nanoparticles as measured by time-resolved terahertz spectroscopy," Nano Letters, vol. 2, no. 9, pp. 983-987, 2002.

[11] R. P. Raffaelle, S. L. Castro, A. F. Hepp, and S. G. Bailey, "Quantum dot solar cells," Progress in Photovoltaics: Research and Applications, vol. 10, no. 6, pp. 433-439, 2002.

[12] V. I. Klimov, A. A. Mikhailovsky, S. Xu et al., "Optical gain and stimulated emission in nanocrystal quantum dots," Science, vol. 290, no. 5490, pp. 314-317, 2000.

[13] S. Gupta, M. Dixit, K. Sharma, and N. S. Saxena, "Mechanical study of metallized polyethylene terephthalate (PET) films," Surface and Coatings Technology, vol. 204, no. 5, pp. 661-666, 2009.

[14] S. Gupta, D. Patidar, N. S. Saxena, K. Sharma, and T. P. Sharma, "Electrical study of Cu-CdS and Zn-CdS schottky junctions," Optoelectronics and Advanced Materials, Rapid Communications, vol. 2, no. 4, pp. 205-208, 2008. 
[15] H. Uda, H. Yonezawa, Y. Ohtsubo, M. Kosaka, and H. Sonomura, "Thin CdS films prepared by metalorganic chemical vapor deposition," Solar Energy Materials and Solar Cells, vol. 75, no. 1-2, pp. 219-226, 2003.

[16] K. Anuar, Z. Zulkarnain, N. Saravanan, M. Nazri, and R. Sharin, "Effects of electrodeposition periods and solution temperatures towards theproperties of CdS thin films prepared in the presence of sodium Tartrate," Materials Science, vol. 11, no. 2, pp. 101-104, 2005.

[17] J. H. Lee and D. J. Lee, "Effects of $\mathrm{CdCl}_{2}$ treatment on the properties of CdS films prepared by r.f. magnetron sputtering," Thin Solid Films, vol. 515, no. 15, pp. 6055-6059, 2007.

[18] P. P. Sahay, R. K. Nath, and S. Tewari, "Optical properties of thermally evaporated CdS thin films," Crystal Research and Technology, vol. 42, no. 3, pp. 275-280, 2007.

[19] S. Gupta, V. Shaktawat, K. Sharma, N. S. Saxena, and T. P. Sharma, "Mechanical property of CdS coated PET and mica films," AIP Conference Proceedings, vol. 1004, no. 1, pp. 328-333.

[20] M. Dixit, V. Shaktawat, K. Sharma, N. S. Saxena, and T. P. Sharma, "Mechanical characterization of polymethyl methacrylate and polycarbonate blends," AIP Conference Proceedings, vol. 1004, no. 1, pp. 311-315.

[21] K. Menard, Dynamic Mechanical Analysis: A Practical Introduction, CRC Press, Boca Raton, Fla, USA, 1999.

[22] W. D. J. Callister, "Characteristics, applications and processing of polymers," in Materials Science and Engineering: An Introduction, W. D. J. Callister and D. G. Rethwisch, Eds., John Wiley \& Sons, 2000.

[23] C. R. Martins, Y. M. De Almeida, G. C. Do Nascimento, and W. M. De Azevedo, "Metal nanoparticles incorporation during the photopolymerization of polypyrrole," Journal of Materials Science, vol. 41, no. 22, pp. 7413-7418, 2006.

[24] P. Ziegler, M. F. Vallat, H. Haidara, and J. Schultz, "Polyester/aluminium adhesion: improvement by heat treatments," Journal of Materials Science, vol. 32, no. 7, pp. 1809-1813, 1997.

[25] S. Lalitha, R. Sathyamoorthy, S. Senthilarasu, A. Subbarayan, and K. Natarajan, "Characterization of CdTe thin filmdependence of structural and optical properties on temperature and thickness," Solar Energy Materials and Solar Cells, vol. 82, no. 1-2, pp. 187-199, 2004.

[26] M. Baboo, M. Dixit, K. Sharma, and N. S. Saxena, "The Structure and thermomechanical properties of blends of transpolyisoprene with cis-polyisopren," International Journal of Polymeric Materials, vol. 58, no. 12, pp. 636-646, 2009.

[27] D. Singh, K. Singh, G. Singh et al., "Optical and structural properties of $\mathrm{ZnO}-\mathrm{PbO}-\mathrm{B}_{2} \mathrm{O}_{3}$ and $\mathrm{ZnO}-\mathrm{PbO}-\mathrm{B}_{2} \mathrm{O}_{3}-\mathrm{SiO}_{2}$ glasses," Journal of Physics: Condensed Matter, vol. 20, no. 7, Article ID 075228, 2008.

[28] R. R. Singh, D. Kaushik, M. Sharma, D. K. Gupta, and R. K. Pandey, "Studies on surface processing and passivation of $\mathrm{p}$ $\mathrm{Hg}_{1-x} \mathrm{Cd}_{x} \mathrm{Te}$," Semiconductor Science and Technology, vol. 23, no. 1, Article ID 015016, 2008.

[29] Z. B. Sun, X. Z. Dong, W. Q. Chen, S. Shoji, X. M. Duan, and S. Kawata, "Two- and three-dimensional micro/nanostructure patterning of CdS-polymer nanocomposites with a laser interference technique and in situ synthesis," Nanotechnology, vol. 19, no. 3, Article ID 035611, 2008. 

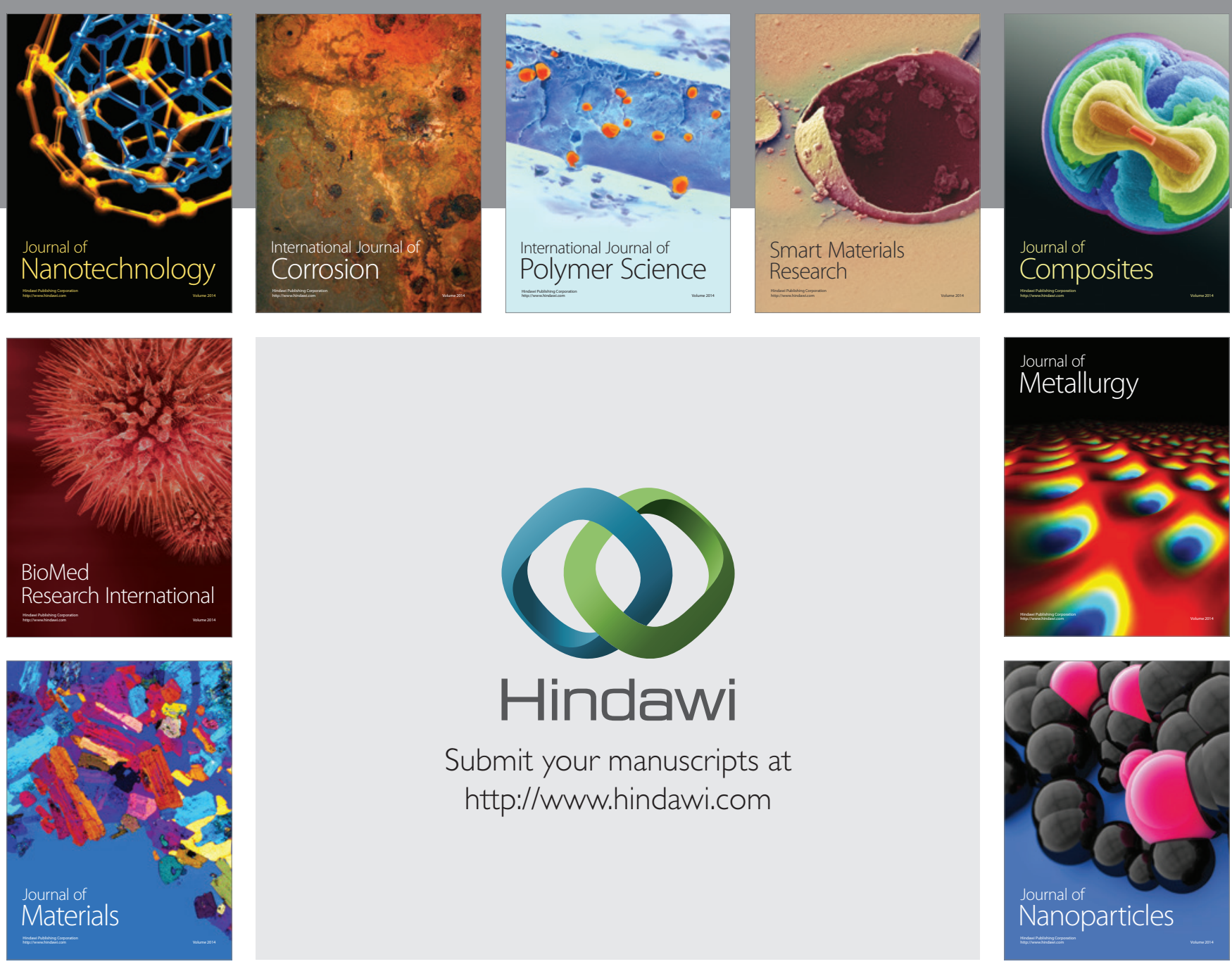

Submit your manuscripts at http://www.hindawi.com
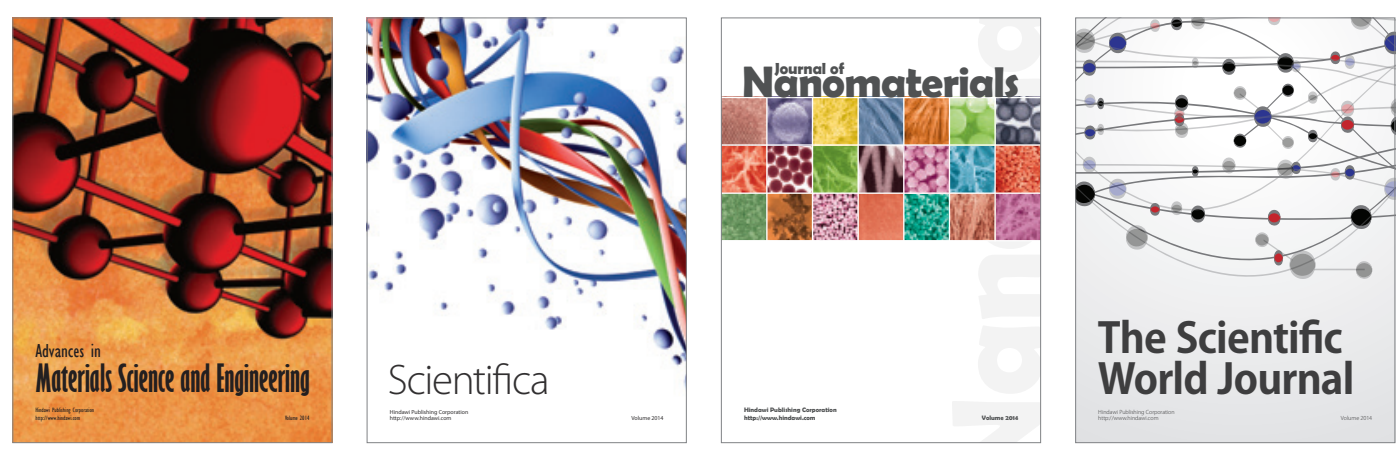

\section{The Scientific World Journal}
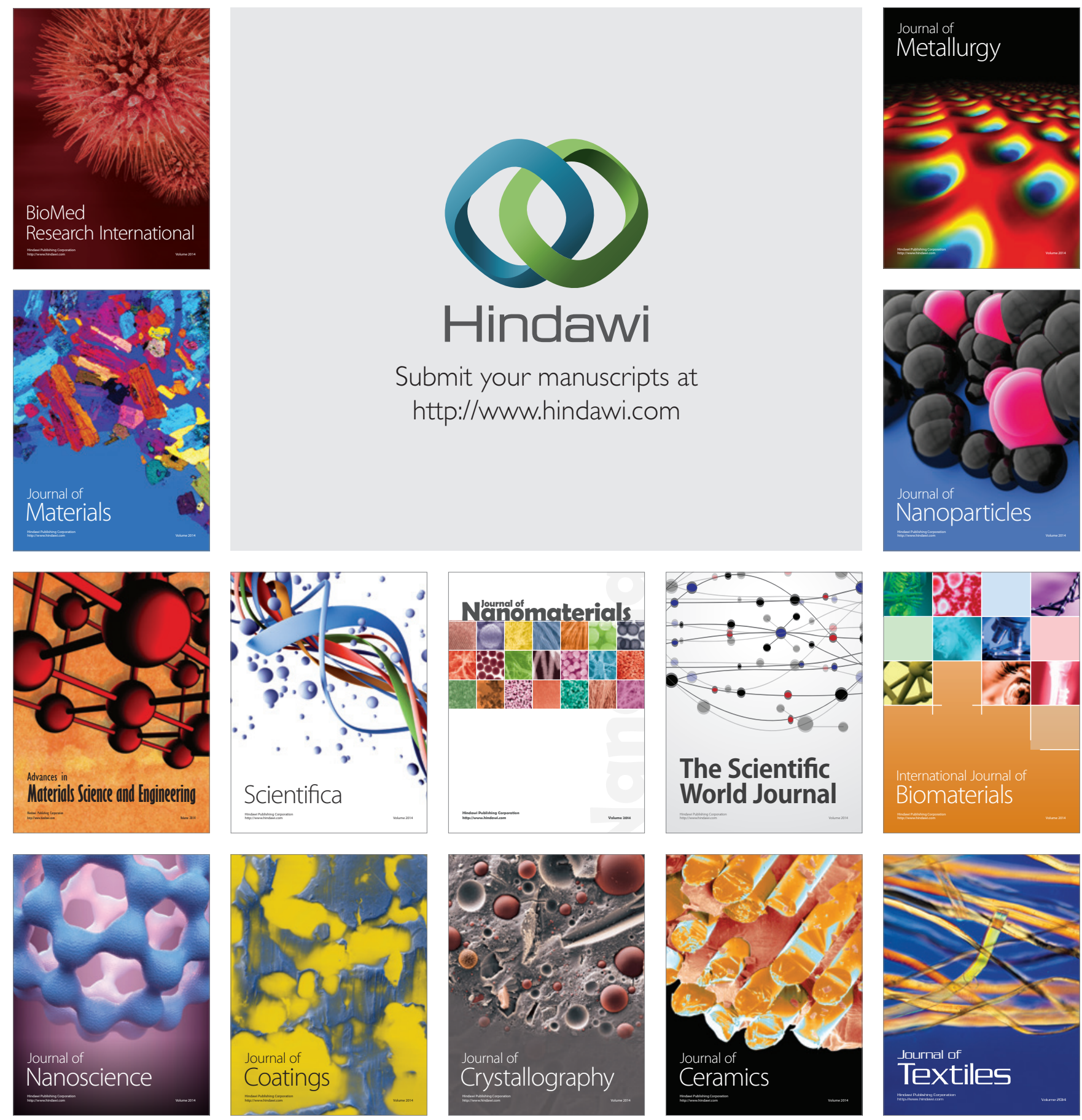